\title{
Effects of Different Preservatives on Cut Flower of Luculia pinceana: A Novel Fragrant Ornamental Species
}

\author{
Lingfang Kong \\ College of Agriculture and Biology Science, Dali University, Dali, China
}

Fan Li

Floriculture Research Institute, Yunnan Academy of Agricultural Sciences, National Engineering Research Center for Ornamental Horticulture, Key Laboratory for Flower Breeding of Yunnan Province, Kunming, China

\section{Ronghui Du}

College of Agriculture and Biology Science, Dali University, Dali, China

\section{Huaiting Geng}

Floriculture Research Institute, Yunnan Academy of Agricultural Sciences, National Engineering Research Center for Ornamental Horticulture, Key Laboratory for Flower Breeding of Yunnan Province, Kunming, China; and School of Agriculture, Yunnan University, Kunming, China

\author{
Shifeng Li and Jihua Wang \\ Floriculture Research Institute, Yunnan Academy of Agricultural Sciences, \\ National Engineering Research Center for Ornamental Horticulture, Key \\ Laboratory for Flower Breeding of Yunnan Province, Kunming, China
}

Additional index words. fresh-keeping, low-sugar preservative, novel ornamentals, vase life

\begin{abstract}
Luculia pinceana is a potential cut flower because of its long-term blooming inflorescences and charming fragrance. However, its narrow distribution area and unexplored wild status severely restrict its applications, thus leading to the scientific research of cut $L$. pinceana flowers. To our knowledge, there is no available published information about the postharvest fresh-keeping of $L$. pinceana. During this study, the cut flowers of $L$. pinceana were tested using nine preservatives with different concentrations of sucrose and 8-hydroxyquinoline (8-HQ) to evaluate the fresh-keeping effects. Through the investigation and analysis of vase life, bud opening and abortion rate, water balance, malonaldehyde (MDA) content, and peroxidase (POD) activity, we selected and identified the best vase solution for cut $L$. pinceana flowers. The results suggested that the preservative of $1 \%$ sucrose and $100 \mathrm{mg} / \mathrm{L} 8$-HQ could significantly prolong the vase life of cut $L$. pinceana flower up to 9 days compared with water control. This solution positively affects flower bud blooming, delays flower senescence, improves the water balance, inhibits the MDA accumulation, and increases POD activity. Therefore, this preservative is suitable for the fresh-keeping of cut $L$. pinceana flowers. Our study is the first to report the effects of preservatives on cut $L$. pinceana flower. The results showed that the low-sugar-containing (1\% sugar) preservatives can effectively improve the ornamental quality of fresh flowers and demonstrated that the postharvest fresh-keeping of $L$. pinceana requires low sugar and is insensitive to microorganisms.
\end{abstract}

Luculia pinceana, a flowering shrub of the Rubiaceae family, is an endangered species on the Red List of Threatened Species made by the International Union for Conservation of Nature [Botanic Gardens Conservation International (BGCI), IUCN SSC Global Tree Specialist Group, 2019]. It is narrowly distributed from the southeast margin of the Tibetan Plateau in southwest China to adjacent northeast Myanmar and northern Vietnam, and can be sporadically seen on limestone mountains, open slopes, secondary shrubby woodland, and roadsides at altitudes between $600 \mathrm{~m}$ and $3000 \mathrm{~m}$ (Chen and Taylor, 2011). This species is of particular interest to floriculturists because of its sweetly fragrant inflorescences with attractive pink to white tubular flowers and extremely long-term blooming period (naturally from April to November). As a consequence, it is widely cultivated in temples, gardens, and public parks as local ornamentals in the distribution areas. In addition to these excellent ornamental characteristics, $L$. pinceana has compact and dense inflorescences with relatively long stems. Therefore, considering its potential as a cut flower species, L. pinceana is a very suitable candidate for development. Because the natural distribution of $L$. pinceana is narrow and the population size is decreasing, this special-interest ornamental plant has not attracted the attention of many scientists, thereby leading to few scientific literatures and limiting the application and production of its cut flower; however, its seed yield is huge and seed germination rate is high. Therefore, the development of this ornamental species as cut flowers with an extended vase life is very practical for improving its wild status and promoting the floricultural industry.

Preservatives comprise commonly used chemicals to delay flower senescence and retain the ornamental value because of their low cost, ease of use, and obvious fresh-keeping effects (Gómez-Merino et al., 2020; Rabiza-Świder et al., 2019; Shabanian et al., 2019). For decades, many protocols or preservatives have been developed for several cut flower species, such as rose (Rosa hybrida), carnation (Dianthus caryophyllus), and gerbera (Gerbera hybrida) (Ren et al., 2017; Seglie et al., 2011; Shabanian et al., 2018). These fresh-keeping techniques were even developed as commercial products and widely used for many cut flowers, like Floralife and Chrysal (Eriadi et al., 2017). According to previous studies of several ornamental cut flowers, the postharvest quality and vase life of cut flowers mainly depend on the water balance and carbohydrate consumption of petals (Arrom and Munné-Bosch, 2012; Bahremand et al., 2014; Fanourakis et al., 2012; van Doorn, 2012). The water balance is mostly interrupted by microorganism proliferation in the vase solution (Bleeksma and van Doorn, 2003), which could be effectively prevented by some germicides (e.g., 8-HQ) (Mahdi Jowkar, 2006). The carbohydrate depletion in petals can be simply solved by supplementing exogenous sucrose in the vase solution. It has been shown by previous studies that vase solution with sugar can positively affect flower opening and prolong flower vase life (Reid and Jiang, 2012; van Doorn, 2004). Moreover, several independent studies reported that the activity of POD decreased but that the content of MDA increased rapidly during flower senescence (Jakhar and Mukherjee, 2014; Sheng, 1999; Song et al., 2014; Shu et al., 2010). The effects of preservative can be detected and evaluated by the changes in protective enzymes activities during florescence and flower senescence, such as the contents of MDA and POD in petals.

To the best of our knowledge, no previous study researched this species as a cut flower, and there has been no research of the preservation of its cut flower. During this study, we explored and investigated the effects of different preservatives on cut L. pinceana flowers to improve its vase life and provide a scientific basis for the development of cut flowers using L. pinceana.

\section{Materials and Methods}

Plant material. The cut flowers of L. pinceana used during this study were randomly collected in a wild field (lat. $25^{\circ} 34^{\prime} 16^{\prime \prime} \mathrm{N}$, long. $100^{\circ} 16^{\prime} 31^{\prime \prime}$ E) (Fig. 1) in Dali, Yunnan 


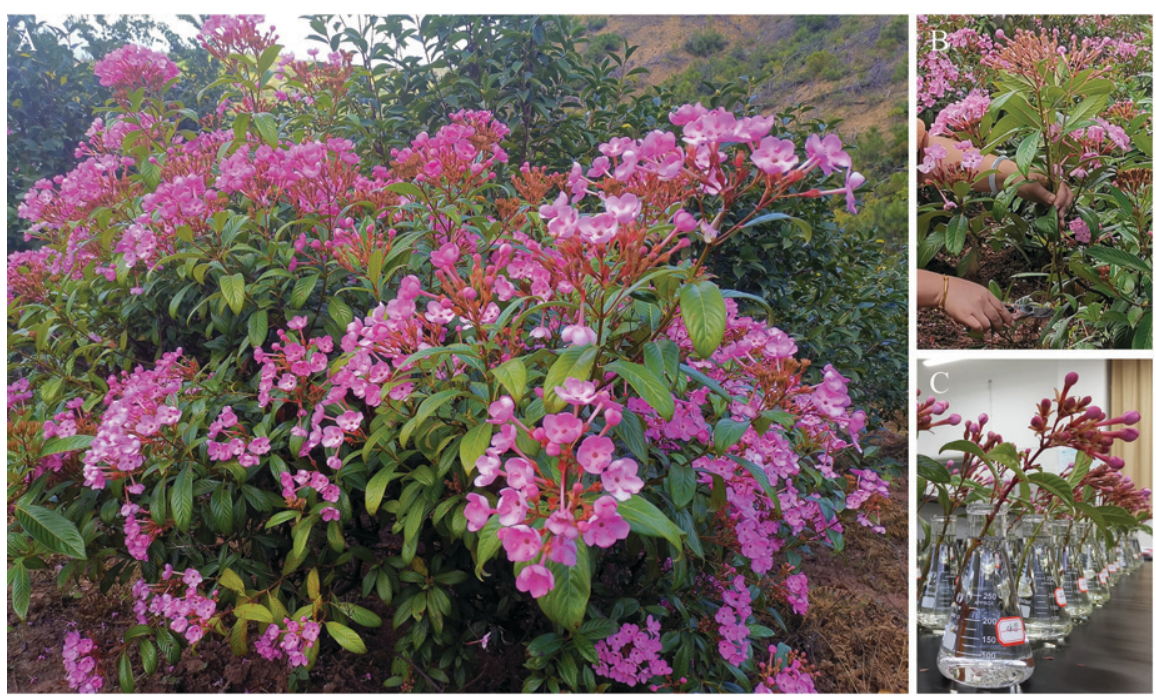

Fig. 1. The flower phenotype of L. pinceana and the treatment for cut flowers. (A) The full-bloom plants in the wild field with attractive fuchsia flowers. (B) The cut branch for the experiment. (C) Treatment of cut flowers in different vase solutions.

Province, at an altitude of $2210 \mathrm{~m}$. The experimental materials were selected from the flower bud stage with the same inflorescence size and without pests, diseases, and mechanical damage. Branches were immediately immersed in the distilled water after being cut from the plant and then quickly transferred to the laboratory. The flower branches were trimmed to $40 \mathrm{~cm}$ at a 45-degree incision with four leaves. Then, these test flower branches were placed in conical flasks with different vase solutions and the bottle was sealed with plastic wrap to prevent moisture from evaporating.

Preservation treatment. The flower branches were treated with nine different vase solutions composed of sucrose $(1 \%, 5 \%$, and $10 \%$ ) and 8 -HQ (50, 100, and $200 \mathrm{mg} /$ L), and a two-factor three-level completely randomized design was used. Additionally, flower branches placed in distilled water (DW) and $30 \mathrm{mg} / \mathrm{L}$ Chrysal solution (Clear, Naarden, the Netherlands) served as controls, and each treatment was repeated three times with one flower branch. The detailed preservatives are shown in Table 1.

The experiments were conducted in an environmentally controlled room with a

Received for publication 29 Jan. 2021. Accepted for publication 7 Apr. 2021.

Published online 2 June 2021.

This work was funded by the Major Science and Technology Project of Yunnan Provincial Science and Technology Department (2019ZG006) and the Green Food Brand -Build a special project (floriculture) supported by science and technology (530000210000000013742).

L.K. and F.L. contributed equally to this work.

S.L. and J.W. are the corresponding authors. E-mail: lishifeng1970@foxmail.com or wjh0505@gmail. com.

This is an open access article distributed under the CC BY-NC-ND license (https://creativecommons. org/licenses/by-nc-nd/4.0/). temperature of $20^{\circ} \mathrm{C}, 60 \%$ relative humidity, and 12-h photoperiod ( $12 \mathrm{~h}$ day/12 $\mathrm{h}$ night; photosynthetic photon flux density of 240 $\mu \mathrm{mol} / \mathrm{m}^{2} / \mathrm{s}$ ). The flowering dynamics were continuously observed until the flowers failed.

Vase life evaluation. The vase life was determined by the phenotype of flower petals; $50 \%$ petals are severely dehydrated or withered spots appeared. The vase life is given as the number of days between placing flower branches into vase solution until the loss of ornamental values as described. We also recorded the bud opening rate and flower abortion rate during the vase period. The bud opening rate is expressed as the percentage of the number of bloom flowers to the total number of flower buds, whereas the flower abortion rate is calculated by comparing the percentage of the number of wilting flower buds to the total number of flower buds.

Water balance analysis. The relative fresh weight and water balance value of cut flowers were measured daily in each treatment using an electronic scale (JY2002; Puchun, Shanghai, China). The relative fresh weight (RFW) of flower branches was calculated using the formula: $\mathrm{RFW} \%=\left(\mathrm{FW}_{\mathrm{d}} / \mathrm{FW}_{0}\right) \times 100 \%$, where $\mathrm{FW}_{\mathrm{d}}$ is the fresh weight of the flower branch at each measuring day (e.g., day 1 , day 2 , day 3 , etc.), and $\mathrm{FW}_{0}$ is the fresh weight of the flower branch at the beginning (day 0$)(\mathrm{He}$ et al., 2006). The water balance value is the difference between water absorption and water evaporation, where water absorption is the solution weight difference between the measuring day and the beginning day, and water

Table 1. Solutions with different preservatives for the treatment of $L$. pinceana cut flowers.

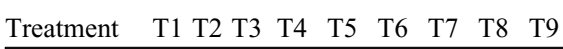
\begin{tabular}{llllllllll}
\hline Sucrose (\%) & 1 & 5 & 10 & 1 & 5 & 10 & 1 & 5 & 10
\end{tabular} 8-HQ $\quad 505050100100100200200200$ $(\mathrm{mg} / \mathrm{L})$

8-HQ $=8$-hydroxyquinoline; $\mathrm{T}$ : treatment. evaporation is the total weight difference of the solution and flower branch between the measuring day and the beginning day.

Determination of physiological parameters. The physiological parameters of cut flowers, MDA content and POD activity, were also investigated every $2 \mathrm{~d}$ using the additional flowers in each treatment. The measurement was performed using a spectrophotometer (T6; Puxi, Beijing, China). The MDA was measured using a thiobarbituric acid reactive substance assay (Hodges et al., 1999). The POD was determined by using the guaiacol method (calorimetric), which has been widely used for the determination of POD activity (Zhao et al., 2015).

Statistical analysis. Data analysis and statistics were performed using Microsoft Excel 2016 and Data Processing System (Tang and Zhang, 2013). One-way analysis of variance with Tukey's honestly significant difference post hoc test was used to compare multiple samples at the 5\% significance level. The data were obtained from three replicates.

\section{Results}

The effect of the vase solution on the vase life. During our study, the preservatives significantly enhanced the vase life of cut $L$. pinceana flowers compared with the control of the distilled water treatment (Fig. 2). The results showed that the vase life in distilled water lasted $13 \mathrm{~d}$, whereas the Chrysal solution (30 $\mathrm{mg} / \mathrm{L}$ ) did increase longevity of the flower to $16 \mathrm{~d}$ (Fig. 3). On the contrary, the vase solutions of T4 (1\% sucrose $+100 \mathrm{mg} / \mathrm{L} 8$-HQ), $\mathrm{T} 7$ (1\% sucrose $+200 \mathrm{mg} / \mathrm{L} 8-\mathrm{HQ})$, and T1 $(1 \%$ sucrose $+50 \mathrm{mg} / \mathrm{L} 8-\mathrm{HQ})$ displayed the longest vase life, which lasted $22 \mathrm{~d}, 21 \mathrm{~d}$, and $20 \mathrm{~d}$, respectively. However, the vase life of all treatments was not been prolonged in a high concentration of sucrose $(10 \%)$, and it was even slightly reduced compared with water control, indicating that high-concentration sugar-containing preservatives do not positively affect the flower vase life of $L$. pinceana. Moreover, regarding sucrose, the lower concentration solutions always extend the vase life in any concentration of 8-HQ solution. Finally, the different effects of 8-HQ and sucrose on fresh-keeping suggested that a regulatory relationship may exist between the chemical concentration and vase day for $L$. pinceana. To explore this possibility, we next assessed the correlation between the concentration of each chemical and the corresponding vase day (Fig. 2 ). The regression analysis revealed that the concentration of sucrose was negatively correlated with the vase day for $L$. pinceana $(\mathrm{y}=$ $\left.-0.9481 \mathrm{x}+21.168 ; R^{2}=0.9038\right)$, whereas there was no correlation between 8-HQ concentration and vase day $(\mathrm{y}=0.0038 \mathrm{x}+$ $15.667 ; R^{2}=0.0042$ ). Through the multiple comparison (Table 2), the concentration of sucrose had significant effects on the vase life of $L$. pinceana $(\mathrm{F}=36.208 ; P=0.0000)$; however, there was no significant effect of $8-\mathrm{HQ}$ concentration on vase life $(\mathrm{F}=1.477 ; P=$ 0.2547 ) and no significant effects on their interaction $(\mathrm{F}=0.058 ; P=0.9933)$. This suggested that the fresh-keeping of cut $L$. 

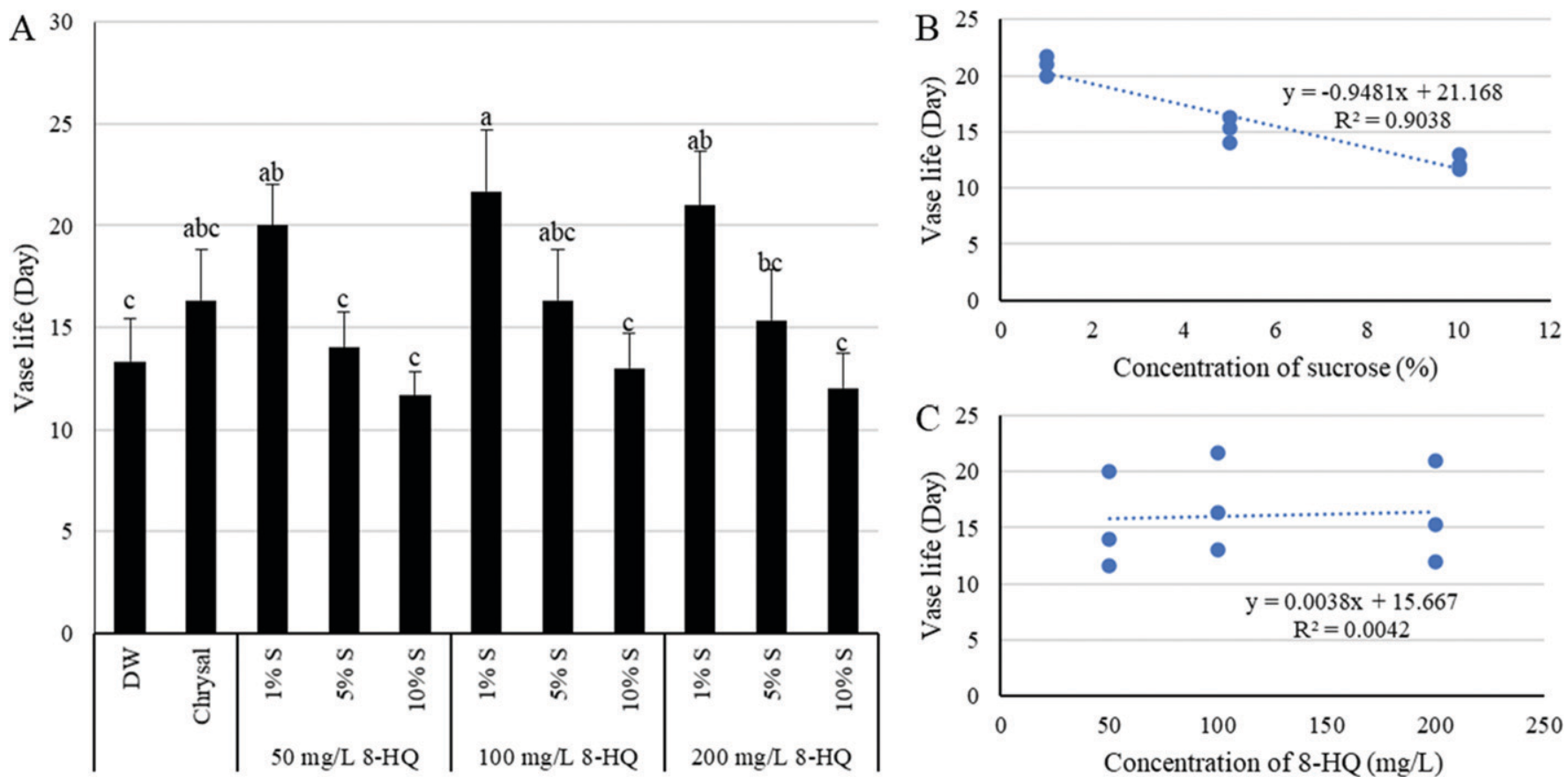

Fig. 2. Effects of preservatives on the vase life of L. pinceana. (A) The average vase life was derived from three replicates and the value is presented as the mean \pm SD $(\mathrm{n}=3)$. A one-way analysis of variance was used to assess statistical significance. $P$ values were calculated with Tukey's honestly significant difference test $(\alpha=0.05)$. DW refers to the distilled water control. The concentration of the Chrysal solution is $30 \mathrm{mg} / \mathrm{L}$. S: sucrose; 8 -HQ: 8-hydroxyquinoline. (B) The correlation analysis of the sucrose concentration and vase life. (C) The correlation analysis of the 8-HQ concentration and vase life.
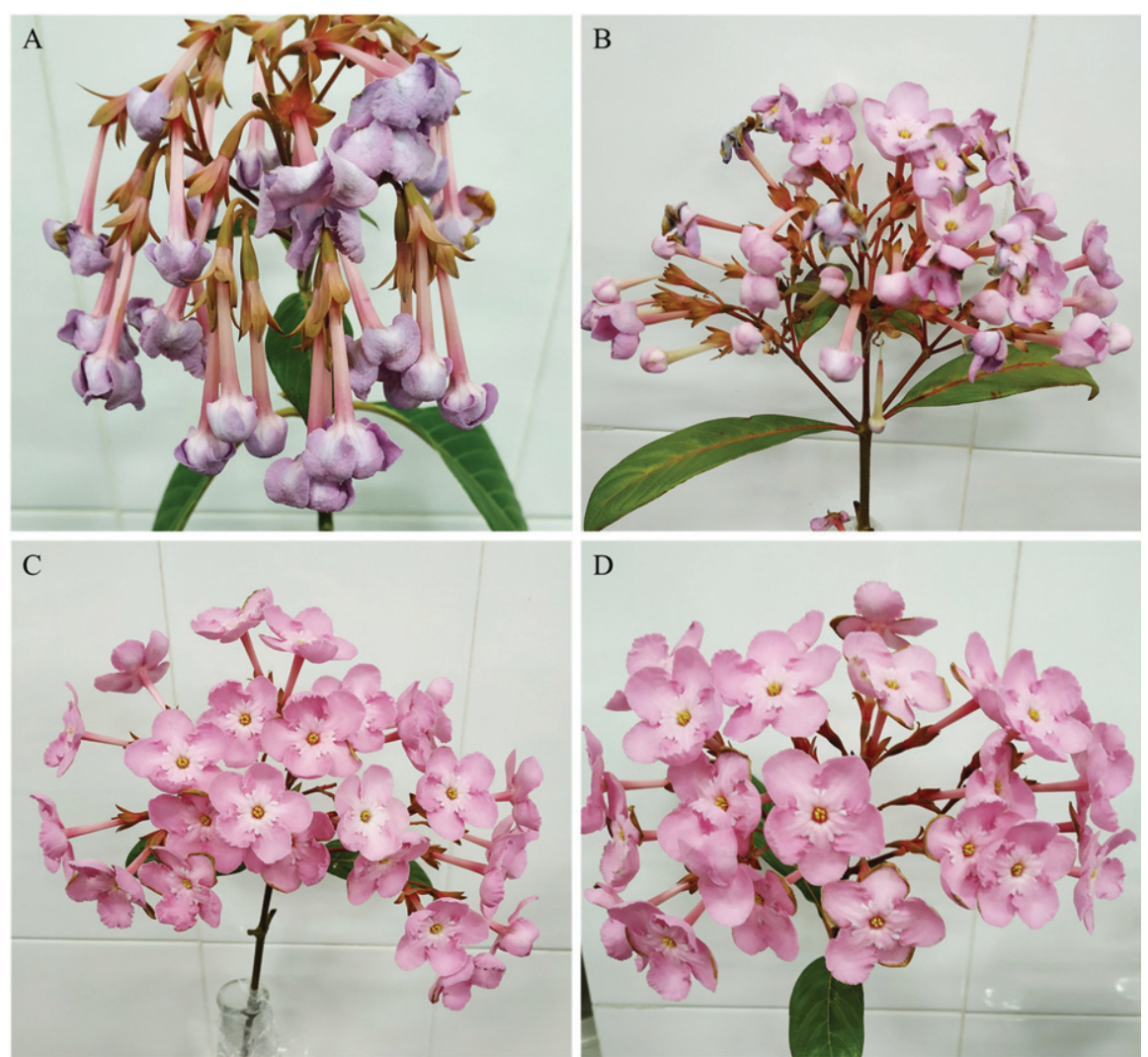

Fig. 3. Flower phenotypes of $L$. pinceana after $13 \mathrm{~d}$ of vase life. (A) The phenotype in the distilled water treatment. (B) The phenotype in the 30-mg/L Chrysal solution. (C) The phenotype in the T4 solution (1\% sucrose and $100 \mathrm{mg} / \mathrm{L} 8-\mathrm{HQ})$. (D) The phenotype in the T7 solution (1\% sucrose and $200 \mathrm{mg} / \mathrm{L} 8-\mathrm{HQ})$ pinceana flowers requires low sugar concentrations and is insensitive to microorganisms.

Effect of vase solution on flower opening and abortion rate. We investigated the dynamics of the bud opening rate in different vase solutions. The results showed that the preservation effect was significantly separated into two groups (Fig. 4). The bud opening rates of treatments $\mathrm{T} 3, \mathrm{~T} 9$, and $\mathrm{T} 6$ and of water control (DW) were less than 30\% (lower group), whereas the other treatments resulted in higher bud opening rates (from $70 \%$ to $100 \%$ ). In the lower group, the flowering time of buds was relatively concentrated within 4 to $10 \mathrm{~d}$, and a large number of flower buds could not open normally, resulting in a lower bud opening rate. Additionally, the higher sugar concentration displayed a similar low bud opening rate compared with that of water control, indicating that the high sugar-containing preservatives cannot promote flower bud opening. Moreover, the $30-\mathrm{mg} / \mathrm{L}$ Chrysal solution could effectively and quickly enhance the blooming of flower buds from the beginning and reach a flowering rate of $20 \%$ on the second day after harvest, but the final bud opening rate was not more than $85 \%$. On the contrary, the low-sugar-containing preservatives ( $11, \mathrm{~T} 4, \mathrm{~T} 7$, and $\mathrm{T} 2$ ) resulted in higher bud opening rates than Chrysal solution; the $\mathrm{T} 1$ and $\mathrm{T} 4$ solution promoted $100 \%$ flower blooming. Furthermore, the T4 solution treatment resulted in more stable and continuous blooming than the T1 solution. Therefore, the T4 solution was considered the best blooming promoter for $L$. pinceana flower buds. Our results showed that flower bud blooming of $L$. 
Table 2. Effects of 8-HQ and sucrose on vase time for L. pinceana.

\begin{tabular}{lccrrr}
\hline Source of variation & Sum of the square & Degrees of freedom & Mean square & F value & $P$ value \\
\hline 8-HQ & 14.2222 & 2 & 7.1111 & 1.477 & 0.2547 \\
Sucrose & 348.6667 & 2 & 174.3333 & 36.208 & 0.0000 \\
8-HQ $\times$ sucrose & 1.1111 & 4 & 0.2778 & 0.058 & 0.9933 \\
Error & 86.6667 & 18 & 4.8148 & & \\
Total variation & 450.6667 & 26 & & & \\
\hline 8
\end{tabular}

8-HQ $=8$-hydroxyquinoline.

pinceana was sensitive to the sugar concentration but insensitive to 8-HQ, demonstrating that the flower opening of $L$. pinceana requires a small amount of sugar accumulation and displays a wide range of flowering adaptability.

We also recorded the dynamics of the flower abortion rate during the vase life, which revealed the effects of preservatives on the fresh-keeping of cut $L$. pinceana flowers. Most treatments could maintain the fresh flowers until the sixth day after harvest, except the T9 treatment (10\% sucrose and $200 \mathrm{mg} / \mathrm{L}$ 8-HQ). Compared with the water control, the solutions with $5 \%$ and $10 \%$ sucrose (T2, T5, $\mathrm{T} 8, \mathrm{~T} 3$, and T6) also resulted in the earlier decline of flowers and showed no improvement in the fresh-keeping of cut L. pinceana flowers. Although the $30-\mathrm{mg} / \mathrm{L}$ Chrysal solution could maintain fresh flowers longer than the water control, the flower abortion rate increased rapidly under both solutions in the end of vase life. Again, we observed that the low-sugar-containing preservatives (T1, T4, and T7) resulted in the best fresh-keeping effects, and the aborted flowers appeared at day 14. This result was in line with our observation that low-sugar-containing preservatives positively affect flower opening, improve flower vase life, and delay flower senescence.

Effect of vase solution on water balance parameters. Two water balance parameters, relative fresh weight and water balance value, were investigated to evaluate the effects of preservatives on cut flowers of $L$. pinceana. The results showed that the water balance parameters were affected by different preservatives, but that their response trends were similar (Fig. 5). With the water control, the relative fresh weight and water balance value reached a peak at day 4 after harvest and then declined rapidly. This indicated that the senescence of flowers has accelerated since day 4, thereby affecting the water transport capacity of branches and, in turn, leading to slower water absorption. Moreover, the water balance parameters varied even more with $\mathrm{T} 3$ solution $(10 \%$ sucrose and 50 $\mathrm{mg} / \mathrm{L} 8-\mathrm{HQ}$ ) than with water control; with the water control, the water balance parameters sharply decreased to the lowest values from day 8 after harvest. Similarly, an inflection point of the water balance parameters was observed in Chrysal, T9, T6, T2, T8, and T5 solutions; however, this inflection point was delayed and appeared on day 12 with $\mathrm{T} 7, \mathrm{~T} 4$, and $\mathrm{T} 1$ solutions, which had low-sugar-containing preservatives. The results suggested that low-sugarcontaining preservatives could significantly promote the water absorption of branches, improve the water balance and supply, and ensure the transportation of other materials (e.g., sugar), thus effectively alleviating the wilting process of fresh flowers, and prolong the vase life of cut flowers. Our results demonstrated that low-sugar-containing preservatives have the best effects
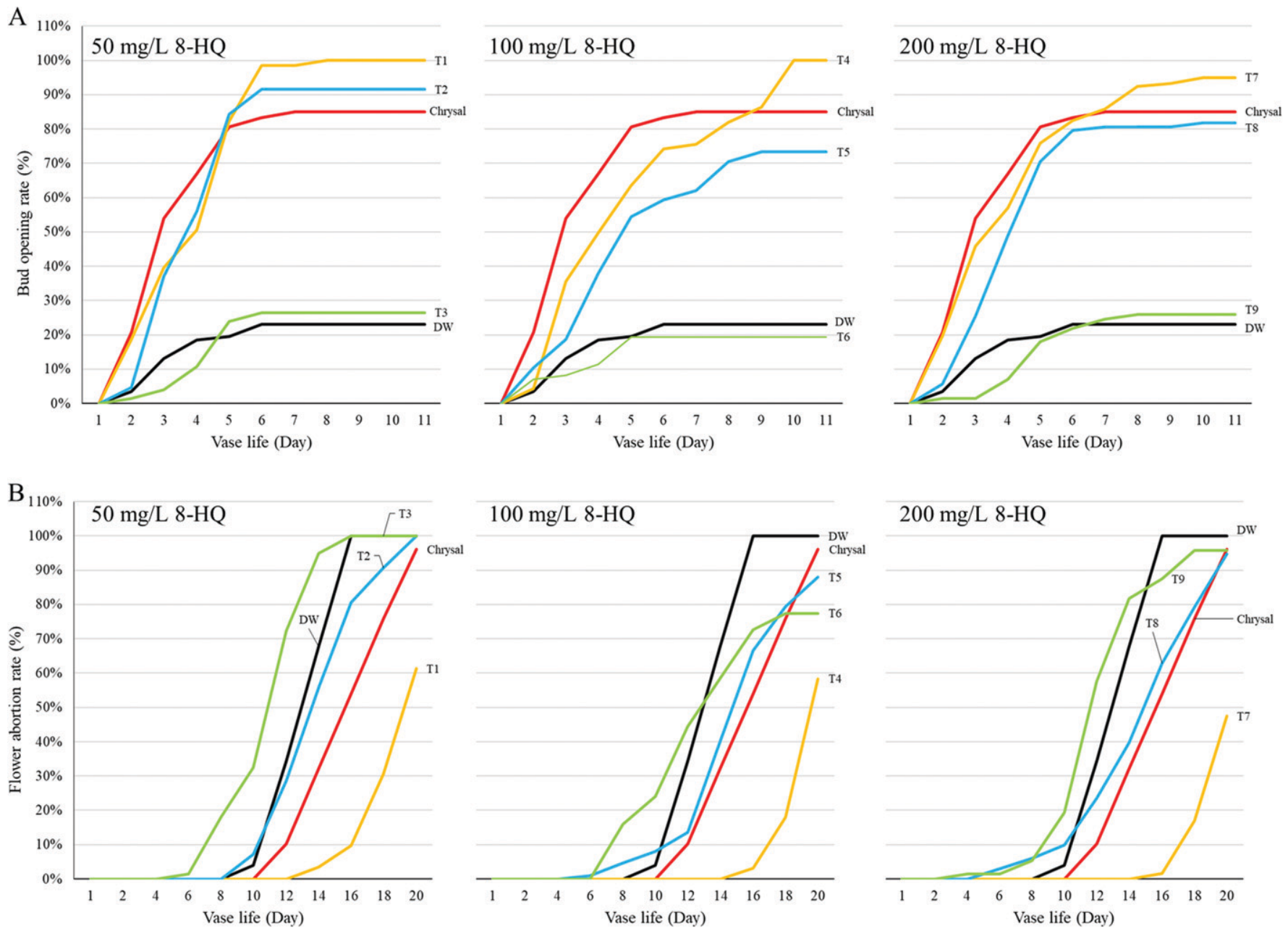

Fig. 4. Effects of different preservatives on the bud opening rate and flower abortion rate of L. pinceana. (A) The dynamic of the bud opening rate in different vase solutions. (B) The dynamic of the flower abortion rate in different vase solutions. The data represent the mean value, which was derived from three replicates. 

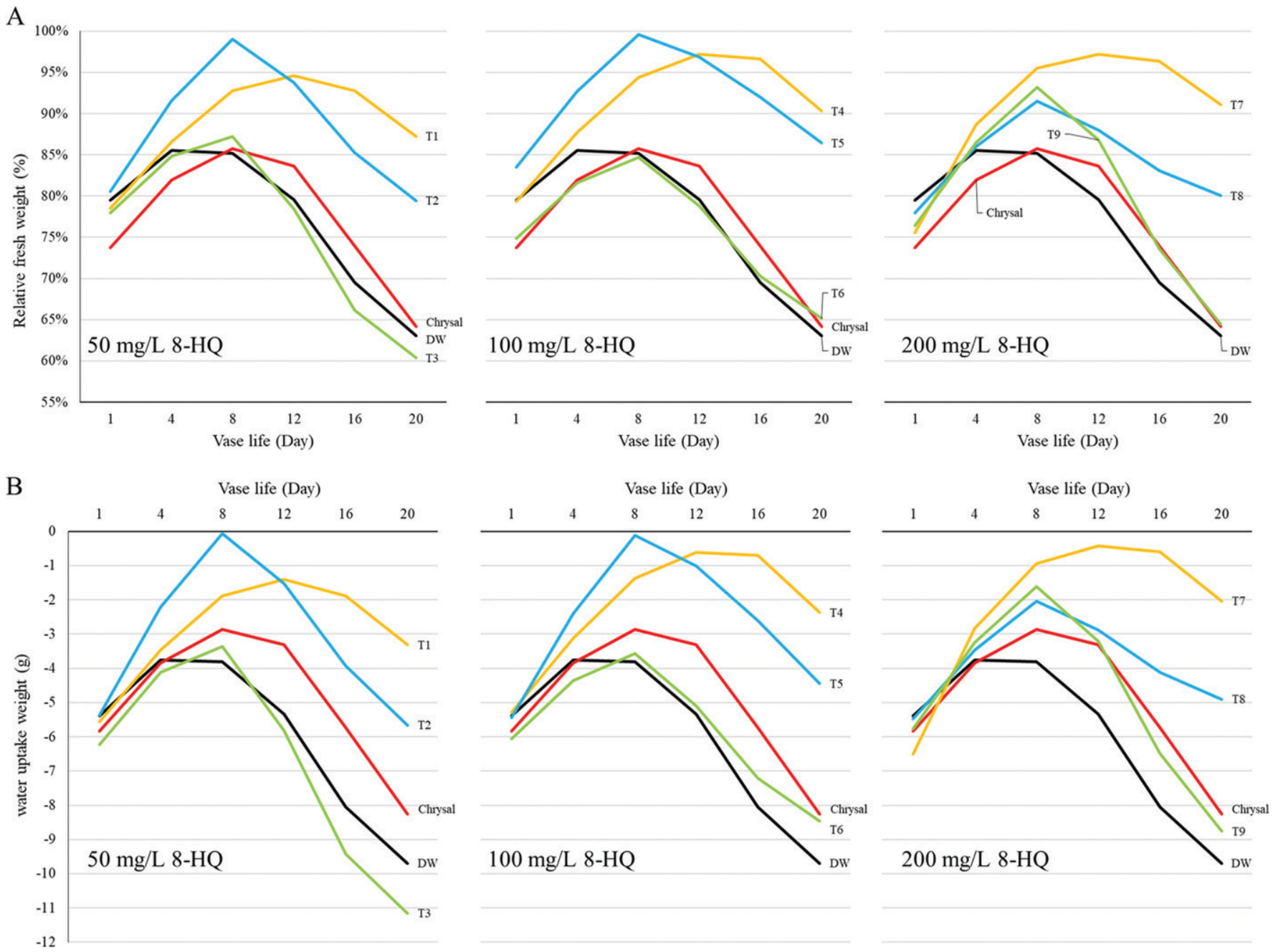

Fig. 5. Effects of different preservatives on the water balance of cut $L$. pinceana flowers. (A) The dynamic of the relative fresh weight in each preservative treatment. (B) The dynamic of the water balance value in each preservative treatment. The data represent the mean value, which was derived from three replicates.

on cut $L$. pinceana flowers and can increase their ornamental value up to $8 \mathrm{~d}$.

Effect of the vase solution on physiological parameters. Finally, we investigated the physiological parameters (MDA and POD) to evaluate the effects of preservatives on cut $L$. pinceana flowers (Fig. 6). The results showed that MDA was largely generated after harvest and decreased during the vase period, with a peak at the end of each treatment, except the water control slowly decreased during the whole vase life. However, the variation tendency of POD was opposite to that of MDA, showing a negatively correlation with an upward trend after harvest with each preservative. The vase solution with low-sugar-containing preservatives could inhibit MDA production and reduce the accumulation of MDA while promoting the POD activity. However, the inhibitory effect on MDA and the promotion effect on POD of Chrysal were better than those of our vase solution, indicating that the preservatives used during this study still need further and deeper optimization.

\section{Discussion}

Luculia pinceana is a shrubby species that has been cultivated as traditional Chinese medicine and ornamentals for a long time; $L$. pinceana was cultured in southwest China as early as the 1560 s and recorded in the Ming Dynasty ancient book Materia Medica of Southern Yunnan (Lan, 1959). As an unexplored wild ornamental, L. pinceana harbored several excellent ornamental characteristics, such as charming fragrance, attractive pink to white tubular flowers, and long-term blooming inflorescences. The high ornamental value of $L$. pinceana attracted the interests of natives, who have cultivated this species widely in temples, gardens, and public parks. However, L. pinceana is an orphan plant in floricultural research that lacks substantial research interest compared with other floricultural species, such as rose, lily, or carnation. Limited studies of the heterogeneity of floral morph and the compounds of flower fragrant in L. pinceana have been performed (Kang et al., 2008; Li et al., 2016; Zhou et al., 2010, 2012, 2015). During this study, we observed the effects of different preservatives on cut $L$. pinceana flowers and selected the best vase solution for fresh-keeping of its cut flowers. According to our results, treatment with lowsugar-containing preservatives, especially the solution containing $1 \%$ sucrose and $100 \mathrm{mg} / \mathrm{L}$
8-HQ, could effectively prolong the vase life of cut $L$. pinceana flowers. Our results provide a simple fresh-keeping protocol for cut $L$. pinceana flowers that has practical value for its development into a floricultural species.

The vase life of cut flowers is an important quality that directly affects their commodity value. Therefore, extending the vase life and delaying flower senescence have attracted the attention of florists worldwide. Therefore, many studies of various species with different preservatives that contain sugars, fungicides, ethylene inhibitors, and growth-regulating substances have been performed (Rogers, 2006). Exogenous sugar and germicide are known to hasten bud opening, prolong flower longevity, improve water balance, and decreases ethylene sensitivity (Baker, 2018; Rabiza-Świder et al., 2020; Reid and Jiang, 2012). The role of sugar in improving the quality of cut flowers has been shown for tulips, lilies, and gerberas; it prolongs their vase life and delays flower senescence (Arrom and Munné-Bosch, 2012; Ranwala and Miller, 2009; Shabanian et al., 2018). It was reported that the vase life of cut rose flowers was extended from 4 to $8 \mathrm{~d}$ in the vase solution containing $5 \%$ sucrose by improving the 

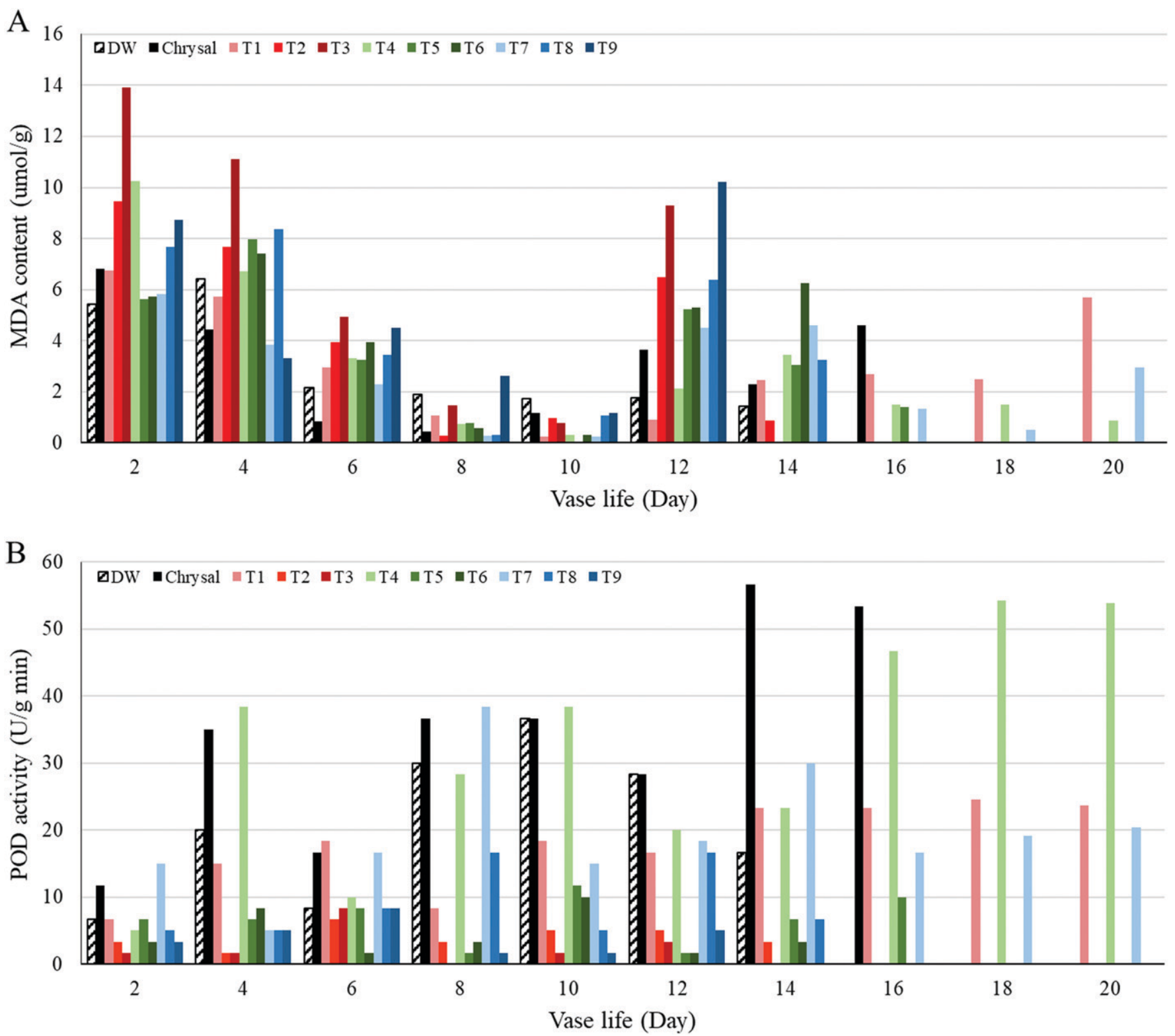

Fig. 6. Effects of different preservatives on malonaldehyde (MAD) and peroxidase (POD) of cut $L$. pinceana flowers. (A) The dynamic of MDA after treatment with different preservatives. (B) The dynamic of POD after treatment with different preservatives. The data represent the mean value, which was derived from three replicates.

carbohydrate supply and reducing oxidative stress-mediated damage during flower senescence (Lama et al., 2015). Moreover, the concentration of $4 \%$ sucrose was the most effective solution for vase life prolongation of Narcissus (Ghale-shahi et al., 2015), and the low sugar content $(2 \%)$ positively affected the flower epidermis of several cut daffodil flowers (Rabiza-Świder et al., 2020). In the present study, our vase solution with low-sugar-containing preservatives ( $1 \%$ sugar) largely improved flower longevity to $9 \mathrm{~d}$, whereas the high-sugar-containing preservatives $(10 \%$ sugar) had no effects on the vase life of $L$. pinceana. The correlation analysis and multiple comparison suggested that there was a strong negative correlation and significant effect between the sugar concentration and vase life. The lower sugar levels also promoted flower bud blooming, delayed flower abortion, improved water balance, and enhanced POD activity compared with higher sugar concentrations. Our results demonstrated that flower freshkeeping of $L$. pinceana requires a low sugar concentration. This may be related to the compounds of flower stems and floral fragrance, such as oils, paeonols, and triterpenoid saponins (Kang et al., 2008; Li et al., 2016), which lead to the low sugar requirements of flowers during blooming. However, it has also reported that the application of sugar-containing preservatives does not always effectively prolong the vase life of some ornamentals, such as bulbous species, because the exogenous sugar is attracted to floral structures other than ornamental petals (Nichols, 1973). Therefore, the higher-sugar preservatives could have blocked the microstructures of stem ends in cut $L$. pinceana flowers during the vase period, thus preventing the sugar and water supplies, resulting in a shorter vase life.

Moreover, the fact that 8-HQ solution can increase flower longevity has been studied in several ornamental species, such as carnation, rose, and hydrangea (Edrisi et al., 2015; Hussen and Yassin, 2013; Kazaz et al., 2019). In a study of cut rose, sucrose mixed with 8-HQ had a better effect on vase life of cut roses than the distilled water control, and 8-HQ with 5\% sucrose prolonged the vase life of cut flowers for a longer period (Lama et al., 2015). According to our results, the preservative composed of 8-HQ and sucrose in several sucrose concentrations $(1 \%, 5 \%$, and $10 \%)$ affected the rate of bud opening and vase life, but the responses and effects varied mainly depending on the sucrose concentration according to the 
correlation analysis and multiple comparison. This may suggest that the fresh flower of $L$. pinceana is insensitive to microorganisms because 8-HQ inhibits the growth of bacteria in the solution. The lack of 8-HQ response may also be caused by hollow flower stems, which are unlikely to be blocked by bacteria and microorganisms.

Finally, the preservatives used during this study displayed an inhibitory effect on MDA and enhanced the activity of POD, which was in line with previously studies (Jakhar and Mukherjee, 2014; Sheng, 1999; Song et al., 2014; Shu et al., 2010). The antagonism between MDA and POD with each preservative treatment indicated that low-sugar solutions have a positive effect on POD activity and reduced the production of MDA, thus alleviating the senescence of flowers, prolonging vase life, and improving the water balance of cut flowers during the vase period. However, the effect of preservatives on physiological changes was not as strong as that of the Chrysal solution; therefore, the formula of preservatives needs to be improved and further developed in the future. Antiethylene compounds should be tested because fragrant flowers are usually affected by ethylene, and flower senescence is very sensitive to ethylene (Gutierrez, 2009).

Our research demonstrated that the preservatives composed of 8-HQ and sucrose could effectively improve the vase life and retain the ornamental value of $L$. pinceana. Among all preservatives, the vase solution of $1 \%$ sugar with $100 \mathrm{mg} / \mathrm{L} 8$-HQ had the best preservation effect on fresh cut flowers of $L$. pinceana; it not only increased the flower bud opening rate and ensured the continuous and stable blooming of flowers but also maintained the fresh weight and water balance of cut flowers, alleviated the accumulation of MDA, improved the POD activity, and effectively prolonged the vase life to $22 \mathrm{~d}$.

\section{Literature Cited}

Arrom, L. and S. Munné-Bosch. 2012. Sucrose accelerates flower opening and delays senescence through a hormonal effect in cut lily flowers. Plant Sci. 188:41-47, doi: 10.1016/j.plantsci. 2012.02.012.

Bahremand, S., J. Razmjoo, and H. Farahmand. 2014. Effects of nano-silver and sucrose applications on cut flower longevity and quality of tuberose (Polianthus tuberosa). Intl. J. Hort. Sci. Technol. 1:67-77, doi: 10.22059/IJHST.2014. 50519.

Baker, J.E. 2018. Preservation of cut flowers, p. 173-188. In: L.G. Nickell (ed.). Plant growth regulating chemicals. Volume II. CRC Press, Boca Raton, FL, doi: 10.1201/9781351075749.

Bleeksma, H.C. and W.G. van Doorn. 2003. Embolism in rose stems as a result of vascular occlusion by bacteria. Postharvest Biol. Technol. 29:335-341, doi: 10.1016/S0925-5214(03)00 049-8.

Botanic Gardens Conservation International (BGCI), IUCN SSC Global Tree Specialist Group. 2019. Luculia pinceana. The IUCN Red List of Threatened Species 2019: E.T146526628A146526630, doi: 10.2305/IUCN.UK.2019-2.RLTS.T1465266 28A146526630.en.
Chen, T. and C.M. Taylor. 2011. Luculia pinciana, p. 214-215. In: Z. Wu and P.H. Raven (eds.) Flora of China. Science Press/Missouri Botanical Garden, Beijing/St. Louis.

Edrisi, B., A. Sadrpoor, and V. Saffari. 2015. Effects of chemicals on vase life of cut carnation (Dianthus caryophyllus L. 'Delphi') and microorganisms population in solution. J. Ornamental Plants 2:1-11, doi: 10.11238/mammalian science.53.311.

Eriadi, I., I. Sukewijaya, and D. Sutedja. 2017. Effect of several concentrations of preservatives Chrysal the tuberose flower freshness (Polianthes tuberosa). Agrotrop 7:79-88.

Fanourakis, D., S.M. Carvalho, D.P. Almeida, O. van Kooten, W.G. van Doorn, and E. Heuvelink. 2012. Postharvest water relations in cut rose cultivars with contrasting sensitivity to high relative air humidity during growth. Postharvest Biol. Technol. 64:64-73, doi: 10.1016/ j.postharvbio.2011.09.016.

Ghale-shahi, Z.G., M. Babarabie, H. Zarei, and A. Danyaei. 2015. Investigating the potential of increasing the vase life of cut flower of Narcissus by using sour orange fruit extract and sucrose in the storage conditions. J. Ornamental Plants 5:21-28, doi: 10.13140/RG.2.1.1786 6009.

Gómez-Merino, F.C., A.M. Castillo-González, M. Ramírez-Martínez, and L.I. Trejo-Téllez. 2020. Lanthanum delays senescence and improves postharvest quality in cut tulip (Tulipa gesneriana L.) flowers. Sci. Rpt. 10:1-12, doi: 10.1038/s41598-020-76266-0.

Gutierrez, A.B. 2009. Studies on fragrance, vase life and ethylene regulation of volatile production in rose flowers. University of Florida, Gainesville, FL.

He, S., D.C. Joyce, D.E. Irving, and J.D. Faragher. 2006. Stem end blockage in cut Grevillea 'Crimson Yul-lo' inflorescences. Postharvest Biol. Technol. 41:78-84, doi: 10.1016/j.postharv bio.2006.03.002

Hodges, D.M., J.M. DeLong, C.F. Forney, and R.K Prange. 1999. Improving the thiobarbituric acidreactive-substances assay for estimating lipid peroxidation in plant tissues containing anthocyanin and other interfering compounds. Planta 207:604-611.

Hussen, S. and H. Yassin. 2013. Review on the impact of different vase solutions on the postharvest life of rose flower. Intl. J. Agr. Res. Rev. 1:13-17, doi: 10.13140/RG.2.1.2133.3528.

Jakhar, S. and D. Mukherjee. 2014. Chloroplast pigments, proteins, lipid peroxidation and activities of antioxidative enzymes during maturation and senescence of leaves and reproductive organs of Cajanus cajan L. Physiol. Mol. Biol. Plants 20:171-180, doi: 10.1007/s12298-013-0219-x.

Kang, W., J. Wang, and Z. Ji. 2008. Flavonoids in $\mathrm{Lu}$ culia pinceana. Chem. Nat. Compd. 44:644-645, doi: 10.1007/s10600-008-9165-1.

Kazaz, S., E. Doğan, T. Kılıç, E. Şahin, and S. Seyhan. 2019. Influence of holding solutions on vase life of cut hydrangea flowers (Hydrangea macrophylla Thunb.). Fresenius Environ. Bull. 28:3554-3559.

Lama, B., M. Ghosal, S. Kumar Gupta, and P. Mandal. 2015. Assessment of different preservative solutions on vase life of cut roses. J. Ornamental Plants 3:171-181.

Lan, M. 1959. Materia medica of southern Yunnan. Yunnan Science \& Technology Co. Ltd., Kunming.

Li, Y., H. Ma, Y. Wan, T. Li, X. Liu, Z. Sun, and Z. Li. 2016. Volatile organic compounds emissions from Luculia pinceana flower and its changes at different stages of flower development. Molecules 21:531, doi: 10.3390/molecules21040531.

Mahdi Jowkar, M. 2006. Water relations and microbial proliferation in vase solutions of Narcissus tazetta L. cv. 'Shahla-e-Shiraz' as affected by biocide compounds. J. Hort. Sci. Biotechnol. 81:656-660, doi: 10.1080/14620316.2006.1151 2120.

Nichols, R. 1973. Senescence and sugar status of the cut flower. Acta Horticulturae: Symposium on Postharvest Physiology of Cut Flowers 41:21-30, doi: 10.17660/ActaHortic.1975.41.2.

Rabiza-Świder, J., E. Skutnik, and A. Jedrzejuk. 2019. The effect of a sugar-containing preservative on senescence-related processes in cut Clematis flowers. Not. Bot. Horti Agrobot. ClujNapoca 47:432-440, doi: 10.15835/nbha472 11379.

Rabiza-Świder, J., E. Skutnik, A. Jẹdrzejuk, and D. Sochacki. 2020. Effect of preservatives on senescence of cut daffodil (Narcissus L.) flowers. J. Hort. Sci. Biotechnol. 95:331-340, doi: 10.1080/14620316.2019.1679042.

Ranwala, A.P. and W.B. Miller. 2009. Comparison of the dynamics of non-structural carbohydrate pools in cut tulip stems supplied with sucrose or trehalose. Postharvest Biol. Technol. 52:91-96, doi: 10.1016/j.postharvbio.2008.10.004.

Reid, M.S. and C.-Z. Jiang. 2012. Postharvest biology and technology of cut flowers and potted plants, p. 1-54. In: J. Janick (ed.). Horticultural reviews. Wiley-Blackwell, Hoboken, NJ, doi: 10.1002/9781118351871.ch1

Ren, P.-J., X. Jin, W.-B. Liao, M. Wang, L.-J. Niu, X.-P. Li, X.-T. Xu, and Y.-C. Zhu. 2017. Effect of hydrogen-rich water on vase life and quality in cut lily and rose flowers. Hort. Environ. Biotechnol. 58:576-584, doi: 10.1007/s13580-0170043-2.

Rogers, H.J. 2006. Programmed cell death in floral organs: How and why do flowers die? Ann. Bot. 97:309-315, doi: 10.1093/aob/mcj051.

Seglie, L., K. Martina, M. Devecchi, C. Roggero, F. Trotta, and V. Scariot. 2011. The effects of 1MCP in cyclodextrin-based nanosponges to improve the vase life of Dianthus caryophyllus cut flowers. Postharvest Biol. Technol. 59:200-205, doi: 10.1016/j.postharvbio.2010.08.012.

Shabanian, S., M.N. Esfahani, R. Karamian, and L.S.P. Tran. 2018. Physiological and biochemical modifications by postharvest treatment with sodium nitroprusside extend vase life of cut flowers of two gerbera cultivars. Postharvest Biol. Technol. 137:1-8, doi: 10.1016/j.postharvbio.2017. 11.009 .

Shabanian, S., M.N. Esfahani, R. Karamian, and L.-S.P. Tran. 2019. Salicylic acid modulates cutting-induced physiological and biochemical responses to delay senescence in two gerbera cultivars. Plant Growth Regulat. 87:245-256, doi: 10.1007/s10725-018-0466-5.

Sheng, A. 1999. Study on dynamics of endogenous hormones and parameters concerned senescence in cut wintersweet flowers. J. Beijing For. Univ. 21:48-53.

Shu, Z., Y. Shi, H. Qian, Y. Tao, and D. Tang. 2010. Distinct respiration and physiological changes during flower development and senescence in two freesia cultivars. HortScience 45:1088-1092, doi: 10.1016/1065-7355(95)90037-3.

Song, L.L., H. Liu, Y.L. You, J. Sun, C. Yi, Y.B. Li, Y.M. Jiang, and J.S. Wu. 2014. Quality deterioration of cut carnation flowers involves in antioxidant systems and energy status. Scientia Hort. 170:45-52, doi: 10.1016/j.scienta.2014.02.035.

Tang, Q.Y. and C.X. Zhang. 2013. Data Processing System (DPS) software with experimental design, statistical analysis and data mining 
developed for use in entomological research. Insect Sci. 20:254-260, doi: 10.1111/j.17447917.2012.01519.x.

van Doorn, W.G. 2004. Is petal senescence due to sugar starvation? Plant Physiol. 134:35-42, doi: 10.1104/pp.103.033084.

van Doorn, W.G. 2012. Water relations of cut flowers: An update, p. 55-106. In: J. Janick (ed.). Horticultural reviews. Wiley-Blackwell, Hoboken, NJ, doi: 10.1002/9781118351871.ch2.
Zhao, Y., L. Yongsheng, and X. Gao. 2015. A new method for accurate determination of peroxidase activity based on fluorescence decrease of guaiacol. Chin. J. Anal. Chem. 43:1040-1046, doi: 10.11895/j.issn.0253-3820.150115.

Zhou, W., S.C. Barrett, H. Wang, and D.Z. Li. 2012. Loss of floral polymorphism in heterostylous $\mathrm{Lu}$ culia pinceana (Rubiaceae): A molecular phylogeographic perspective. Mol. Ecol. 21:4631-4645, doi: 10.1111/j.1365-294X.2012.05707.x.
Zhou, W., S.C. Barrett, H. Wang, and D.Z. Li. 2015. Reciprocal herkogamy promotes disassortative mating in a distylous species with intramorph compatibility. New Phytol. 206: 1503-1512, doi: 10.1111/nph.13326.

Zhou, W., H. Wang, D.-Z. Li, and J.-B. Yang. 2010. Isolation and characterization of $13 \mathrm{mi}-$ crosatellite loci from Luculia pinceana (Rubiaceae), a typical distylous species. HortScience 45:840-841, doi: 10.21273/HORTSCI.45.5.840. 